\title{
The effect of residual stress on mixed-mode crack propagation behavior in friction stir welded 7075-T6 aluminum alloy panel under biaxial loading
}

\author{
Xiushuo Zhang ${ }^{1}$, Yu E Ma², Zhenhai Wang ${ }^{1}$, and Yanning Guo ${ }^{2}$ \\ ${ }^{1}$ Northwestern Polytechnical University \\ ${ }^{2}$ Northwestern Polytechnical University School of Aeronautics
}

October 19, 2020

\begin{abstract}
In this work, the effect of residual stress on mixed-mode crack propagation behavior in friction stir welded (FSW) 7075-T6 panel under biaxial loading was investigated. The cruciform sample was designed and manufactured by FSW. Residual stress profiles across the welded sample were measured by the X-ray diffraction technique. Crack propagation behaviors were simulated with five different biaxial loading ratios. Stress intensity factors $\left(K_{I}\right.$ and $\left.K_{I I}\right)$ were evaluated by finite element method (FEM) and used to study the effects of residual stress on crack behaviors. It was observed that residual stress has a considerable effect on the mixed-mode crack growth. In most of the cases, the crack deflection is mainly affected by residual stress at the beginning of crack propagation. The variation of crack propagation path is strongly linked with the residual stress as well as the biaxial loading ratio. In addition, $K_{I}$ and $K_{I I}$ are susceptible to residual stress under biaxial loading conditions. Residual stresses contribute to a higher proportion of $K_{I I}$ compared to that of $K_{I} . K_{I}$ and $K_{I I}$ in the retreating side are more affected by the residual stress.
\end{abstract}

\section{Hosted file}

Manuscript.pdf available at https://authorea.com/users/348957/articles/487572-the-effect-ofresidual-stress-on-mixed-mode-crack-propagation-behavior-in-friction-stir-welded-7075t6-aluminum-alloy-panel-under-biaxial-loading

\section{Hosted file}

Table.pdf available at https://authorea.com/users/348957/articles/487572-the-effect-ofresidual-stress-on-mixed-mode-crack-propagation-behavior-in-friction-stir-welded-7075t6-aluminum-alloy-panel-under-biaxial-loading

\section{Hosted file}

Figure.pdf available at https://authorea.com/users/348957/articles/487572-the-effect-ofresidual-stress-on-mixed-mode-crack-propagation-behavior-in-friction-stir-welded-7075t6-aluminum-alloy-panel-under-biaxial-loading 